Canadian

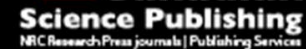

Canadian Journal of Chemistry Revue canadienne de chimie

\title{
Electrodeposition of metal cations from the wet ionic liquid [EMIM][TFSI]
}

\begin{tabular}{|r|l|}
\hline Journal: & Canadian Journal of Chemistry \\
\hline Manuscript ID & cjc-2015-0308.R1 \\
\hline Manuscript Type: & Article \\
\hline Date Submitted by the Author: & 09-Oct-2015 \\
\hline Keyword: & $\begin{array}{l}\text { Electrodeposition, wet ionic liquid, possible application to mining wastes } \\
\text { Shamble } \\
\text { Bejan, Dorin; University of Guelph, } \\
\text { Bunce, Nigel; University of Guelph, Chemistry }\end{array}$ \\
\hline &
\end{tabular}




\section{Electrodeposition of metal cations from the wet ionic liquid [EMIM][TFSI]}

4 Matthew Deen, Christina Shamshoom, Alison Gamble, Dorin Bejan, and Nigel J. Bunce* Electrochemical Technology Centre Chemistry Department, University of Guelph 50 Stone Road East Guelph, Ontario, Canada N1G 2W1

Abstract

We investigated the deposition of silver, copper, and lead from the ionic liquid 1-

12 ethyl-3-methylimidazolium bis(trifluoromethylsulfonyl) imide [EMIM][TFSI] under

13 potentiostatic conditions in the presence of water. This was part of a larger project

14 involving the extraction of metal ions from mining waste into an ionic liquid, followed by

15 electrodeposition so that the ionic liquid could be recycled. All three elements were

16 deposited in metallic form by electrolysis in the ionic liquid, and the process was

17 enhanced rather than hindered by the presence of water. The deposited metals did not

18 adhere strongly to the cathode of the electrochemical cell, especially when Ebonex ${ }^{\mathrm{TM}}$ was

19 used as the cathode. The deposition of silver showed little temperature dependence, and

20 at temperatures close to ambient, the ionic liquid was not adversely affected. The

21 deposits of copper and lead gradually re-dissolved after electrodeposition, suggesting that

22 chemical re-oxidation of these metals by air is more facile in the ionic liquid than in

23 water. Copper showed strong evidence of formation of $\mathrm{a} \mathrm{Cu}^{+}$species upon reduction of

$24 \mathrm{Cu}^{2+}$ (not seen in water); lead $\left(\mathrm{Pb}^{2+}\right)$ showed evidence of a time-dependent complexation

25 with the anions of the ionic liquid.

27 Key words: electrodeposition; ionic liquids; possible application to mining wastes 


\section{Introduction}

Ionic liquids (IL, salts with melting points $<\sim 100^{\circ} \mathrm{C}$ ) typically have high

32 chemical stability, negligible vapour pressure, and high ionic conductivity. ${ }^{1}$ These

33 properties are highly tunable by varying the structures of their constituent ions. ${ }^{2}$ The

34 literature on electrodeposition of metals from ionic liquids ${ }^{3}$ is mainly focused on

35 obtaining novel forms of metal powders such as nano-particles, ${ }^{4}$ or on deposition of

36 elements that cannot be reduced in water: semimetals such as germanium, and metals

37 such as calcium and aluminum. ${ }^{5}$ These applications require scrupulously dry ionic

38 liquids that have wide electrochemical windows. ${ }^{1}$

39 World-wide demand for minerals produces large amounts of wastes. ${ }^{6}$ The present

40 research considers the development of a possible technology for the remediation of toxic

41 metals from aqueous mining wastes. ${ }^{7,8}$ This concept involves extraction of metal cations

42 from the aqueous medium into an IL, using a supported liquid membrane. Subsequent

43 electro-deposition of the elemental metals would regenerate clean IL for recycling back

44 to the extraction step, with the metals recovered either as a saleable byproduct, or in the

45 worst case in a form that could be readily land-filled. In contrast with the anhydrous

46 conditions generally employed in previous studies, the IL would be wet. Hence, this

47 exploratory study involves proof of concept for the electrodeposition of silver, lead and

48 copper, from 1-ethyl-3-methylimidazolium bis(trifluoromethylsulfonyl) imide

49 [EMIM][TFSI] (Figure 1), with emphasis on whether the process is adversely affected 50 by water.

\section{Materials and Methods}

1-Ethyl-3-methyl-imidazolium bis(trifluoromethylsulfonyl) imide 99\%, was

54 purchased from Ionic Liquids Technologies, and stored by filling the bottle with argon

55 after each use. Working solutions were prepared using silver (I) triflate (Sigma Aldrich

$56 \geq 99 \%$ ), lead (II) trifluoroacetate (Alfa Aesar, 98\%) and copper (II) triflate (Alfa Aesar

$57 \geq 99 \%$ ).

58

59 Electrochemical studies: Cyclic voltammetry was conducted using DY2100 potentiostat

60 software and a three-electrode cell comprised of a Pt working electrode (area $3.1 \mathrm{~mm}^{2}$ ), 
61 Pt foil counter electrode, and a Pt wire quasi-reference electrode, at a scan rate of $0.02 \mathrm{~V}$

$62 \mathrm{~s}^{-1}$. The working electrode was cleaned after each use with abrasive paper, and all

63 electrodes were washed using ethanol, de-ionized water, and Milli-Q water, then oven

64 dried; they were cooled for 5 min prior to voltammetric studies.

65 Electrolyses were conducted potentiostatically using a Princeton Applied Research

66 Model 273A potentiostat/galvanostat (Gamble Technologies Limited, Mississauga, ON).

67 Solutions were electrolyzed open to the air, except that argon was bubbled through those

68 that had been previously dried in vacuum. Reactions were conducted using graphite or

69 Ebonex ${ }^{\circledR}$ cathodes, $\mathrm{Pt}$ or $\mathrm{Ti} / \mathrm{IrO}_{2}-\mathrm{Sb}_{2} \mathrm{O}_{5}$ anodes, and $\mathrm{Pt}$ reference electrodes $(\sim+0.7 \mathrm{~V}$ vs

70 SHE), with gentle magnetic stirring.

72 Physical Studies: FTIR analyses were conducted on a solution of $50 \mathrm{mM}\left(\mathrm{CF}_{3} \mathrm{CO}_{2}\right)_{2} \mathrm{~Pb}$

73 in [EMIM][TFSI] using Thermoelectron Nicolet 380 instrumentation with Ez-Omnic

74 software (Madison, WI). Sampling was obtained using attenuated total reflectance

75 methods on a ZnSe crystal, with a resolution of $6 \mathrm{~cm}^{-1}$, and 30 scans per acquisition.

$76 \quad{ }^{207} \mathrm{~Pb}$ NMR (Bruker Avance 300, Milton, ON) was conducted using 1.0 M

$77 \mathrm{~Pb}\left(\mathrm{NO}_{3}\right)_{2}$ in $\mathrm{D}_{2} \mathrm{O}$ as a reference $(\delta=-2990 \mathrm{ppm})$, using $83.5 \mathrm{MHz}$ instrumentation. IL

78 solutions analyzed were $0.5 \mathrm{M}\left(\mathrm{CF}_{3} \mathrm{CO} 2\right){ }_{2} \mathrm{~Pb}$ in [EMIM] [TFSI] with $10 \% \mathrm{v} / \mathrm{v}$ DMSO-d $\mathrm{d}_{6}$.

79 Quantitative water analyses were performed using a Metrohm $870 \mathrm{KF}$

80 (Mississauga, ON) volumetric Karl Fischer titrator using the average of three injected

81 samples of an approximate mass of $0.1 \mathrm{~g}$.

82

83 Qualitative analysis: Silver was identified by dissolving the deposit in nitric acid and

84 adding chloride to give a photosensitive precipitate. Copper was identified through its

85 inability to dissolve in non-reducing acids (sulfuric acid, hydrochloric acid) and its

86 solubility in nitric acid. Powder X-Ray diffraction using a 2-Theta goniometer

87 configuration on an Agilent Technologies SuperNova X-ray diffractometer (Oxfordshire,

88 UK) confirmed the identity of lead deposits.

89

90 Quantitative analysis: Silver remaining in solution was analyzed using a voltammetric

91 calibration curve (see above). Copper analysis employed an Agilent 240 atomic 
92 absorption spectrometer (Mississauga, ON) using a copper metal hollow cathode lamp

93 and a calibration curve with copper (II) triflate. The samples run were prepared by taking

$9435 \mu \mathrm{L}$ samples using a micropipette and dissolving them in water while stirring in a $5 \mathrm{~mL}$

95 volumetric flask. Lead was analyzed gravimetrically by washing the deposits with

96 ethanol and water, followed by thorough drying. In later experiments, all metals were

97 analyzed in triplicate using optical detection ICP, using a Varian Vista-MPX CCD

98 Simultaneous ICP-OES with ICP Expert Software (Mulgrave Victoria, Australia).

99 Wavelengths: silver, 328.068; copper, 327.395; lead, $220.353 \mathrm{~nm}$; plasma gas flow, 15.0

$100 \mathrm{~L} \mathrm{~min}^{-1}$; auxiliary gas flow, $1.50 \mathrm{~L} \mathrm{~min}^{-1}$; nebulizer gas flow, $0.70 \mathrm{~L} \mathrm{~min}^{-1}$.

101

3. Results and Discussion

Dry [EMIM][TFSI] has an electrochemical window of $4.6 \mathrm{~V}$ (from $-2.5 \mathrm{~V}$ to +2.1

104 V vs. Pt quasi reference electrode). ${ }^{9}$ The Digi-Ivy potentiostat used in this work had a

105 range of only $\pm 2 \mathrm{~V}$ vs Pt (approximately -1.3 to $+2.7 \mathrm{~V}$ vs. SHE), which was adequate

106 for the present purposes. "Dry" IL was obtained by treating the solvent as supplied (950

107 ppm water by Karl-Fischer titration) in vacuum for $35 \mathrm{~min}$. Upon adding water, the

108 negligible voltammetric currents obtained with dry IL gave way to voltammograms

109 showing the reduction and oxidation of water, and the electrochemical window shrank to

$110 \sim 2.3 \mathrm{~V}$, as previously reported. ${ }^{10}$

111 The direct extraction of metal ions into ILs did not afford solutions of well-defined

112 solute concentration. We therefore used metal triflates or trifluoroacetates to produce

113 solutions with well-defined initial concentrations, rather than solutions produced by

114 extraction from the aqueous phase. Reference silver solutions were prepared by

115 dissolving $\mathrm{Ag}(\mathrm{I})$ triflate in [EMIM][TFSI] with gentle mixing. To prepare lead solutions,

116 a weighed amount of lead (II) trifluoroacetate was vortexed with [EMIM][TFSI] in a

117 volumetric flask for approximately 10-15 min; the flask was then warmed in a water bath

118 while stirring the contents, and finally vortexed for $5 \mathrm{~min}$. Copper (II) triflate, which is

119 anhydrous, was negligibly soluble in dry [EMIM][TFSI], so the IL was saturated with

120 water by forming an emulsion with water for $30 \mathrm{~min}$ before adding the copper salt, then

121 vortexed for a few minutes to complete dissolution. 


\subsection{Silver}

When silver was extracted into [EMIM][TFSI] from aqueous $\mathrm{AgNO}_{3}$, cyclic

126 voltammetry at graphite showed a reversible reduction peak near $-0.2 \mathrm{~V}$ vs. $\mathrm{Pt}$ (which has

$127 \mathrm{E}=+0.7$ vs SHE, and which was originally standardized vs SCE). The oxidation peak on

128 the reverse scan was seen near $+0.07 \mathrm{~V}$ (Figure 2) with a larger current with onset $>1 \mathrm{~V}$

129 due to oxidation of the water that was co-extracted into the IL (not shown). Cyclic

130 voltammograms also showed a noticeable change between the first and subsequent

131 cycles, possibly involving changes to the graphite surface during the oxidation step. ${ }^{11}$

132 The peak current was proportional to (scan rate) ${ }^{1 / 2}$, showing that the reduction of $\mathrm{Ag}^{+}$was

133 electrochemically reversible and took place under mass transport (Supplementary

\section{Figure 1).}

135 Because [EMIM][TFSI] is more viscous than water, we anticipated faster mass

136 transport and hence accelerated deposition in a warm solution. In practice, the peak

137 current increased only two-fold between room temperature and $100^{\circ} \mathrm{C}$ (data not shown).

138 The voltammetric current for the reduction of silver increased slightly with higher water

139 content, showing that water in the IL would not inhibit electrodeposition. Previously,

140 Basile et al. reported that increasing the water content from $60 \mathrm{ppm}$ to $460 \mathrm{ppm}$ lowered

141 the peak current and shifted the potential for $\mathrm{Ag}^{+}$reduction to more negative values in the

142 ionic liquid, $\left[\mathrm{C}_{4} \mathrm{mPyr}\right][\mathrm{TFSI}]$ at a glassy carbon microelectrode. ${ }^{1}$ They suggested that the

143 cause was interaction of $\mathrm{Ag}^{+}$with the pyridinium nitrogen atom of [ $\left.\mathrm{C}_{4} \mathrm{mPyr}\right][\mathrm{TFSI}]$,

144 which is not present in [EMIM][TFSI]. ${ }^{12}$

145 Planar graphite cathodes, formed by cutting $6 \mathrm{~mm}$ diameter graphite rods, were

146 fitted into a $10 \mathrm{~mL}$ beaker that contained $5 \mathrm{~mL}$ of silver triflate in [EMIM][TFSI]. Initial

147 electrolyses were carried out potentiostatically at $-0.19 \mathrm{~V}$ vs Pt quasi reference electrode,

148 and followed by cyclic voltammetry using a calibration curve prepared with standard

149 solutions of silver triflate in [EMIM][TFSI] (Supplementary Figure 2). For this work

150 the potentiostatic method was more convenient, and assured that first order kinetics

151 would be followed. This avoided the issue of the competition between current controlled

152 and mass transport controlled kinetics. 
153 The reactions were run to $\sim 50 \%$ conversion with water content up to near154 saturation of $\sim 10,000 \mathrm{ppm}$. The current density (reaction rate) increased significantly at 155 higher water content; the current efficiency was essentially quantitative, independently of 156 the water content (Table 1, entries 1, 3, and 4). The systematic trend of $>100 \% \mathrm{CE}$ in 157 these experiments is almost certainly the result of experimental uncertainty, due to the 158 experimental difficulty of calibrating the voltammetric method of quantitative analysis 159 precisely. Later experiments were analyzed by ICP-OES, which gave more reproducible 160 results.

161 The initial relationship between accumulated charge and time was relatively 162 rapid, but then became linear (Figure 3). This was attributed to an initial deposition of 163 silver onto graphite, with subsequent deposition onto a rough silver surface. The current

164 density also increased at elevated temperature, as observed previously. ${ }^{13}$ At $78^{\circ} \mathrm{C}$ with IL 165 as received (950 ppm water), the water content is recorded as "unknown" because the 166 experiment was carried out in an open beaker, so water evaporated as the electrolysis 167 progressed. Discolouration of the IL was observed above $78^{\circ} \mathrm{C}$, suggesting 168 decomposition. Although the cyclic voltammograms were run up to $\sim 100^{\circ} \mathrm{C}$, the 169 electrodepositions were not run beyond $78^{\circ} \mathrm{C}$ once this discolouration was noticed. In 170 addition, the inability to maintain a defined water concentration, because of evaporation 171 at this elevated temperature, made the results ambiguous. However, the lack of a strong 172 temperature effect was important for the proposed technology, because it rebutted any 173 suggestion that the waste stream should be heated before electrolysis. Specific energies 174 for silver deposition were approximately $3 \mathrm{kWh}(\mathrm{kg} \mathrm{Ag})^{-1}$ in repeated experiments at $175 \sim 10,000 \mathrm{ppm}$ water, and double this at $78^{\circ} \mathrm{C}$.

176 Later experiment employed Ebonex ${ }^{\mathrm{TM}}$ cathodes (a conductive ceramic of 177 approximate composition $\left.\mathrm{Ti}_{4} \mathrm{O}_{7}\right) \cdot{ }^{14,15}$ As at graphite, the silver deposit adhered poorly to 178 the cathode and was easily removed. In experiments analyzed by ICP, silver was 179 deposited from undried [EMIM][TFSI] with almost quantitative current efficiency at $180 \quad 0.27 \mathrm{~V}$ vs Pt. The rate increased when water was added to a total concentration of 10,000 181 ppm, with little reduction of the current efficiency (though the reaction was still 182 considerably slower than in fully aqueous solution. At $-0.40 \mathrm{~V}$, the reaction was faster 183 but somewhat less efficient, due to competing reduction of water (Figure 4). 


\subsection{Copper}

Commonly available copper salts were insoluble in dry [EMIM][TFSI].

Saturation with water $(\sim 12,000 \mathrm{ppm})$ was necessary before adding copper triflate (a white powder). The resulting solution had the light blue colour characteristic of $\mathrm{Cu}^{2+}(\mathrm{aq})$. two reduction peaks experiments: one near $-0.6 \mathrm{~V}$ and another near $-0.3 \mathrm{~V}$ vs Pt quasi reference (Figure 5). These were assigned to the reduction of $\mathrm{Cu}(\mathrm{II})$ to $\mathrm{Cu}$ (I) and the subsequent reduction of $\mathrm{Cu}(\mathrm{I})$ to $\mathrm{Cu}(0),{ }^{12}$ based on the visual observation that no deposit was formed on the cathode upon electrolysis at $-0.10 \mathrm{~V}$ even though current was flowing (showing that reduction was occuring), whereas rapid deposition of copper occurred upon electrolysis at $\sim-0.60 \mathrm{~V}$. A linear calibration curve for copper was obtained at the first reduction peak (Supplementary Figure 3) with $i$ (peak) $\alpha$ (scan rate) $)^{1 / 2}$, indicating reduction under mass transport control (Supplementary Figure 4). At an Ebonex cathode, reduction peaks were observed with current maxima at $-0.39 \mathrm{~V}$ and $-1.02 \mathrm{~V}$ vs. Pt.

Graphite cathodes were not studied for the "bulk" deposition of copper, because the two reduction peaks were poorly separated, and so the appearance of the voltammograms changed with water content and temperature. Also, there was an initial confusion in identifying the electrolysis product at graphite - a black deposit $(\mathrm{CuO})$ that

204 dissolved easily in dilute mineral acids to give a faint blue aqueous solution of $\mathrm{Cu}^{2+}(\mathrm{aq})$.

205 Murase et al. had identified a black deposit as $\mathrm{Cu}$ metal by XRD analysis, but from a 206 different ionic liquid. ${ }^{16}$

In "bulk" $(5 \mathrm{~mL})$ solutions, the rate of loss of copper from the IL varied with the

\section{9 deposit, as with silver (Supplementary Table 1). Copper was distinguished from its}

210 oxides $\left(\mathrm{CuO}\right.$ and $\left.\mathrm{Cu}_{2} \mathrm{O}\right)$ because the oxides were soluble in dilute mineral acids, whereas

211 copper metal dissolved only in moderately concentrated nitric acid.

212 At Ebonex, copper deposition was observed visually upon electrolysis at $-0.39 \mathrm{~V}$,

213 but was less efficient at $-1.02 \mathrm{~V}$ due to preferential reduction of water to $\mathrm{H}_{2}$ (supported by 214 a large increase in current density when the solution was acidified). We cannot say 
215 conclusively whether the deposition observed at $-0.39 \mathrm{~V}$ was due to 2-electron reduction 216 of $\mathrm{Cu}(\mathrm{II})$ to $\mathrm{Cu}$ metal, or to reduction of $\mathrm{Cu}$ (II) to $\mathrm{Cu}(\mathrm{I})$, followed by disproportionation 217 in the somewhat aqueous medium. Evidence supporting the latter mechanism is that $218 \mathrm{Cu}(\mathrm{I})$ appears to be more stable in [EMIM][TFSI]. The oxidation of copper powder in 219 contact with copper(II) triflate in [EMIM][TFSI] solution provided evidence for the 220 reverse of disproportionation, literature precedent for which is the conversion of $\mathrm{Cu}(\mathrm{II})$ 221 and copper metal to $\mathrm{Cu}(\mathrm{I})$ in [EMIM] [dicyanamide]. ${ }^{12}$ Additional evidence for 222 accumulation of $\mathrm{Cu}(\mathrm{I})$ in solution during the electrolysis of copper triflate in 223 [EMIM][TFSI], using an Ebonex cathode and $\mathrm{Ti} / \mathrm{IrO}_{2}-\mathrm{Ta}_{2} \mathrm{O}_{5}$ anode, was that there was 224 initially no loss of copper from the solution, until $3 \mathrm{C}$ of charge had passed (Figure 6). 225 This suggests that that any $\mathrm{Cu}$ metal that is deposited redissolves through the "reverse 226 disproportionation" process - until the concentration of $\mathrm{Cu}$ (II) has become negligible. 227 The deposition of copper was faster (and continuous from time zero) at more cathodic 228 potentials, but the current efficiency was lower due to competing reduction of water. When a solution of $\mathrm{Cu}(\mathrm{II})$ triflate was electrolyzed with sparging to remove water, 230 copper was lost from solution with $80 \%$ apparent current efficiency. However, this was 231 an artefact: the solution gradually became cloudy due to evaporation of water and 232 precipitation of $\mathrm{Cu}(\mathrm{II})$ triflate, which redissolved when water was re-added.

233 Unexpectedly, the copper particles formed by electrolysis gradually dissolved

234 when left in contact with the IL, with the smallest particles dissolving fastest. The 235 oxidation of $\mathrm{Cu}$ metal by $\mathrm{O}_{2}$ is thermodynamically favourable; it appears to be kinetically 236 favourable in the ionic liquid, unlike in air or water, where it is so slow that copper is 237 regarded as stable in these media. Besides molecular $\mathrm{O}_{2}$ from the atmosphere, oxidizing 238 species during the electrolysis include $\mathrm{O}_{2}$ and hydroxyl radicals formed by the oxidation 239 of water at the anode (balancing the reduction of $\mathrm{Cu}(\mathrm{II})$ at the cathode). Deposition of 240 copper (or inhibition of redissolution) was mildly improved by excluding adventitious 241 oxygen, by carrying out the electrolyses under a blanket of argon, and by using the 242 dimensionally stable anode $\mathrm{Ti} / \mathrm{IrO}_{2}-\mathrm{Ta}_{2} \mathrm{O}_{5}$ to minimize the formation of hydroxyl 243 radicals. ${ }^{17}$ The deposition of copper was very inefficient at elevated temperature, perhaps 244 because of faster re-dissolution, unlike the deposition of silver, which was almost 245 insensitive to temperature. 


\section{$247 \quad 3.3 \quad$ Lead}

248 A solution of lead bis-trifluoroacetate in [EMIM][TFSI] (950 ppm water) showed 249 a principal voltammetric reduction peak at $\sim-1.3 \mathrm{~V}$ vs. Pt (more negative than that for 250 silver or copper). However, the voltammograms changed in appearance with both water 251 concentration (Supplementary Figure 5) and time (Supplementary Figure 6), showing 252 that the interaction between $\mathrm{Pb}^{2+}$ and the $\mathrm{IL}$ is extremely complex. Hence the 253 voltammograms represent contributions from both free and probably multiple forms of 254 complexed lead cations. Most of the change occurred over $\sim 2 \mathrm{~h}$ (the reduction peak near $255-1.3 \mathrm{~V}$ shifted to less negative potentials by about $0.1 \mathrm{~V}$, while the broader peak near -0.6 $256 \mathrm{~V}$ gained in intensity). Consequently, we could neither prepare calibration curves by 257 voltammetry nor examine the effects of temperature and scan rate.

258 We suggest that aging caused a chemical change to the lead bis(trifluoroacetate) 259 solution, perhaps due to complexation of $\mathrm{Pb}^{2+}$ with either the cation or more likely, the 260 anion of the ionic liquid. We attempted to study this phenomenon by ${ }^{207} \mathrm{~Pb}$ NMR (spin $261 \pm 1 / 2,22.6 \%$ natural abundance, receptivity $11.7 \times$ that of ${ }^{13} \mathrm{C}$ ), which has a particularly 262 wide chemical shift range that is highly sensitive to both the number and type of atoms 263 that is coordinated to the lead centre. ${ }^{18}$ Unfortunately, there is little information on the

$264{ }^{207} \mathrm{~Pb}$ analysis of soluble $\mathrm{Pb}(\mathrm{II})$ compounds - most work on ${ }^{207} \mathrm{~Pb}$ has involved soluble $265 \mathrm{~Pb}(\mathrm{IV})$ and solid state $\mathrm{Pb}(\mathrm{II})$ systems.

266 We hoped to use NMR to follow chemical shift changes in fresh and aged 267 solutions of lead bis(trifluoroacetate) in [EMIM][TFSI]. Reference spectra for $\mathrm{Pb}\left(\mathrm{NO}_{3}\right)_{2}$ 268 in $\mathrm{D}_{2} \mathrm{O}$ and $\left(\mathrm{CF}_{3} \mathrm{CO}_{2}\right)_{2} \mathrm{~Pb}$ were obtained in $\mathrm{DMSO}-\mathrm{d}_{6}$ using a deuterium lock to reference 269 the signal due to ${ }^{207} \mathrm{~Pb}$, and hence avoid broadening the resonances due to small 270 instrumental changes between pulses. Peak broadening, along with the relatively low 271 concentration of $\mathrm{Pb}$, obstructed our inability to observe ${ }^{207} \mathrm{~Pb}$ NMR spectra in 272 [EMIM][TFSI]. Hayamizu et al. have reported that the ${ }^{1} \mathrm{H}$ and ${ }^{19} \mathrm{~F}$ NMR spectra of 273 [EMIM][TFSI] show strong peak broadening, ${ }^{19}$ due to the T2 spin-spin relaxation time 274 being much shorter than the T1 spin-lattice relaxation time. ${ }^{20}$ We therefore hoped to 275 observe "free" $\mathrm{Pb}^{2+}$ in a freshly prepared solution, followed by its "disappearance" due to 276 peak broadening as it complexed to the IL. This was not feasible because the acquisition 
277 of a ${ }^{207} \mathrm{~Pb}$ NMR spectrum required $>2 \mathrm{~h}$, by which time the presumed complexation had 278 already occurred.

279 DFT calculations indicate that [TFSI] can act as a bidentate ligand, in which the 280 oxygen atoms can coordinate a metal cation. ${ }^{21}$ FTIR spectrometry in the range 1100$2811200 \mathrm{~cm}^{-1}$ gave tentative evidence for complexation of lead to the TFSI anion. The 282 spectrum of the pure solvent agreed well with that reported. ${ }^{22}$ Subtraction of the 283 spectrum of pure solvent from that of $50 \mathrm{mM}$ lead bis(trifluoroacetate) in [EMIM][TFSI] 284 showed changes in the $\mathrm{S}=\mathrm{O}$ stretching frequencies near $1130 \mathrm{~cm}^{-1}$. This is suggestive, 285 but not diagnostic, of complexation between $\mathrm{Pb}^{2+}$ cations and TFSI anions

286 (Supplementary Figure 7).

287 Electrolyses were carried out using graphite and Ebonex cathodes. At graphite, the 288 grey deposit of lead from [EMIM][TFSI] was hard to distinguish from the colour of the cathode. With a Pt counter electrode, a dark, shiny red-yellow deposit of lead oxide,

290 soluble in dilute mineral acid, appeared on the anode. This was not observed at $\mathrm{Ti} / \mathrm{IrO}_{2}-$

$291 \mathrm{Sb}_{2} \mathrm{O}_{5}$. At Ebonex ${ }^{\circledR}$, the product comprised medium-to-small grey powder clusters,

292 which were filtered, washed thoroughly, and dried before weighing. Possible errors

293 include failure to capture the smallest particles, which would cause underestimation of

294 the current efficiency, expressed as (mol Pb as weighed/mol e $\mathrm{e}^{-}$from coulometry) $\times(2$

$295 \mathrm{~mol} \mathrm{\textrm {e }}-/ 1 \mathrm{~mol} \mathrm{~Pb})$. Powder x-ray diffraction confirmed that the particles were indeed

296 lead, and not a lead oxide; the reference lead powder was obtained by electrochemical

297 deposition of lead from lead nitrate solution (Supplementary Figure 8).

298 The current efficiency varied with both the water content and the aging of the

299 solutions being electrolyzed (Supplementary Table 2). As with copper, the lead

300 precipitate redissolved when left in contact with the IL after electrolysis, and solubilized

301 completely within $24 \mathrm{~h}$. Some of the smallest particles re-dissolved during the time that it

302 took to filter the larger particles. There is literature precedent for oxidation and

303 solubilization of metallic lead upon contact with oxygenated water through the historic

304 use of lead pipes for drinking water, though this process is very slow. ${ }^{20}$

305 Wet [EMIM][TFSI] gave faster electrodeposition but with a higher proportion of

306 very small particles, whose redissolution may account in part for the lower current

307 efficiency under these conditions (Figure 7). Aged solutions also had lower current 
308 efficiency, consistent with complexation between $\mathrm{Pb}^{2+}$ and the IL. The specific energy

309 consumption for deposition of lead from a $3 \mathrm{mM}$ solution was slightly higher than from a

310 fresh $20 \mathrm{mM}$ solution, but with significantly lower current efficiency.

\section{$312 \quad 3.4 \quad$ Metal mixtures}

313 A single experiment with simultaneous deposition of silver, copper, and lead from

314 [EMIM][TFSI] showed the expected preferential deposition $\mathrm{Ag}>\mathrm{Cu}>\mathrm{Pb}$ at $-1.2 \mathrm{~V}$ vs

$315 \mathrm{Pt}$, a potential that was sufficiently cathodic for all three metals to be deposited (Figure

316 8). No attempt was made in this work to achieve electroseparation.

\section{Conclusions}

In this study, silver, copper, and lead were electrodeposited from a representative IL, [EMIM][TFSI]. Current efficiencies approached 100\% under potentiostatic conditions at which water reduction was minimized. Otherwise, the presence of water was not disadvantageous to the process. From the chemical perspective, the

324 evidence of the intermediate formation of a $\mathrm{Cu}(\mathrm{I})$ species in the IL, and lead showed 325 evidence of complexation to the IL. The deposits of both copper and lead were found to 326 redissolve in contact with the IL $(\mathrm{Pb}>\mathrm{Cu})$, suggesting that solvent [EMIM][TFSI]

327 enhances the rate of the thermodynamically favourable oxidation process.

328 This work was carried out to offer proof of concept for electrodeposition from wet 329 ionic liquids. Although not examined experimentally in this work, the literature on 330 electrodeposition of metals from anhydrous ILs ${ }^{23-26}$ suggests that this should be a general 331 phenomenon. More particularly, if this approach should be developed into a technology,

332 we would use cation-selective ILs ${ }^{27-33}$ which would allow the recovery of specific

333 contaminants from the waste stream. A further constraint is that the IL selected must 334 have negligible solubility in water ([EMIM][TFSI] does not qualify). Otherwise the loss 335 of IL to the aqueous phase during the extraction phase of the process (see Introduction) 336 would make the technology completely uneconomic. No cost estimates for a technology 337 have been made at this time, pending resolution of these critical issues, which must be 338 explored in the next phase of the work. 
A further consideration in the context of selective extraction into the IL is the

340 need to discriminate against the uptake of $\mathrm{Fe}^{3+}$, which has been shown by Hatfield et

341 al. $^{34,35}$ to interfere with the electrodeposition of copper (in that example) because of

342 reoxidation of the deposited metal. In other words, $\mathrm{Fe}^{3+}\left(\mathrm{E}^{\circ}=+0.77 \mathrm{~V}\right.$ in aqueous

343 solution) is easily able to oxidize both $\mathrm{Cu}$ and $\mathrm{Pb}$ metals.

344 To apply these results towards an eventual technology, we envisage a system in

345 which the aqueous phase is in contact with a membrane-supported IL, with the metal

346 cation(s) transported across the membrane from water into a separate compartment

347 containing the IL. ILs are now available tailored for high affinity for specific metals,

348 offering the option of selective extraction. Electrodeposition could then take place either

349 in a separate chamber with a recycle loop, or even statically on the IL side of the

350 supported membrane. With no requirement to keep the IL anhydrous, the

351 electrodeposition unit could be open to the atmosphere, with facile periodic removal of

352 the cathodes for metal recovery.

353

\section{5. Acknowledgements}

355 We thank the Natural Sciences and Engineering Research Council of Canada for

356 financial support through their Engage program, and Persego Inc. for both in-kind

357 support and interest in the development of a possible technology.

358

359 
361 Figure 1. 1-ethyl-3-methylimidazolium bis(trifluoromethylsulfonyl) imide [EMIM][TFSI].

364 Figure 2. Multiple cycles of voltammetry for the electrodeposition of $\mathrm{Ag}^{0}$ at a graphite

365 (pencil lead) microelectrode; continuous: first cycle; dashed: second and third cycle;

366 dotted: ionic liquid alone.

368 Figure 3. Coulometry plot of the potentiostatic electrolysis of $22.11 \mathrm{mmol} / \mathrm{L} \mathrm{Ag}^{+}$in 369 [EMIM][TFSI] at $-0.19 \mathrm{~V}$ vs. Pt reference electrode.

Figure 4. Depletion of silver in potentiostatic electrolysis of silver triflate in ionic liquid using Ebonex ${ }^{\circledR}$ cathode (-0.27 V vs. Pt wire reference electrode, diamonds, current efficiency $98 \%$ and at $-0.40 \mathrm{~V}$ vs. Pt wire reference electrode, squares, current efficiency $79 \%$ ) and in ionic liquid with added water (from 1000 to 10000 ppm) using Ebonex ${ }^{\circledR}$ cathode (at -0.27 V vs. Pt wire reference electrode, triangles, current efficiency $91 \%$ at 75 min) compared with depletion of silver in potentiostatic electrolysis of silver nitrate in de-ionized water using Ebonex ${ }^{\circledR}$ cathode (at -0.27 V vs. Pt wire reference electrode, circles, current efficiency $85 \%$ at $40 \mathrm{~min}$ ); anode: $\mathrm{Ti} / \mathrm{IrO}_{2}-\mathrm{Sb}_{2} \mathrm{O}_{5}$.

380 Figure 5. Overlay of the voltammograms of blank [EMIM][TFSI] and a solution of 381 [EMIM][TFSI] containing $16.56 \mathrm{mmol} / \mathrm{L}$ of copper triflate using a platinum working

382 electrode with a surface area of $0.0314 \mathrm{~cm}^{2}$.

384 Figure 6. Loss of total copper during potentiostatic electrolysis at high water and oxygen 385 content (not dried and not sparged) at ambient temperature with quantification using 386 FAAS.

388 Figure 7. Depletion of lead in potentiostatic electrolysis of lead (II) trifluoroacetate, in 389 ionic liquid and $76 \mu \mathrm{L}$ milliQ water using Ebonex ${ }^{\circledR}$ cathode (-1.204 V vs. Pt wire 390 reference electrode) and $\mathrm{Ti} / \mathrm{IrO}_{2}-\mathrm{Sb}_{2} \mathrm{O}_{5}$ anode. Current efficiency: 111\% (220 min). 
391 Figure 8. Depletion of lead (diamonds), copper (squares) and silver (triangles) in

392 potentiostatic electrolysis of a mixture of lead (II) trifluoroacetate, copper (II) triflate and

393 silver (I) triflate using Ebonex ${ }^{\circledR}$ cathode (-1.204 V vs. Pt wire reference electrode) and

$394 \mathrm{Ti} / \mathrm{IrO}_{2}-\mathrm{Sb}_{2} \mathrm{O}_{5}$ anode. Current efficiency: $26 \%$ for $\mathrm{Ag}(240 \mathrm{~min}), 29 \%$ for $\mathrm{Cu}$ (480 $\mathrm{min}$ )

395 and $22 \%$ for $\mathrm{Pb}(480 \mathrm{~min})$.

396 
398 (1) Basile, A.; Bhatt, A. I.; O’Mullane, A. P.; Bhargava, S. K. Electrochim. Acta 2011, $39956,2895$.

400 (2) Del Pópolo, M. G.; Voth, G. A. J. Phys. Chem. B. 2004, 108, 1744.

401 (3) Katayama, Y.; Fukui, R.; Miura, T. J. Electrochem. Soc. 2013, 160, D251.

402 (4) Liua, Z.; Zein El Abedin, S.; Endres, F. Electrochim. Acta 2013, 89, 635.

403 (5) Abbott, A. P.; Frisch, G.; Ryder, K. S. Annu. Rev. Mater. Res. 2013, 43, 335.

404 (6) Statistics Canada. 2012. Human Activity and the Environment - Waste management in 405 Canada. Statistics Canada Catalogue no. 16-201-X.

406 (7) Akcil, A.; Koldas, S. J. Cleaner Prod. 2006, 14, 1139.

407 (8) Johnson, M. S.; Roberts, R. D.; Hutton, M; Inskip, J. Oikos. 1978, 30, 153.

408 (9) Matsumoto, H.; Sakaebe, H.; Tatsumi, K.; Kikuta, M.; Ishiko E.; Kono, M. J. Power 409 Sources 2006, 160, 1308.

410 (10) O’Mahony, A. M.; Silvester, D. S.; Aldous, L.; Hardacre, C.; Compton, R. G. J. 411 Chem. Eng. Data 2008, 53, 2884.

412 (11) Rueffer, M.; Bejan, D.; Bunce, N. J. Electrochim. Acta 2011, 56, 2246.

413 (12) Reyna-González, J. M.; Torriero, A. A.; Siriwardana, A. I.; Burgar, I. M.; Bond, A. 414 M. Analyst 2011, (36), 3314.

415 (13) Jacquemin, J.; Husson, P.; Padua, A. A. H.; Majer, V. Green Chem. 2006, 8, 172.

416 (14) Walsh, F. C.; Wills, R. G. A. Electrochim. Acta 2010, 55 , 6342.

417 (15) Bejan, D.; Malcolm, J. D.; Morrison, L.; Bunce, N. J. Electrochim. Acta 2009, 54, 4185548.

419 (16) Murase, K.; Nitta, K; Hirato, T.; Awakura, Y. J Appl. Electrochem. 2001, 31, 1089.

420 (17) Bunce, N. J.; Bejan, D. Encyclopedia of Applied Electrochemistry Springer-Verlag:

421 Berlin Heidelberg, 2014; 1435.

422 (18) Claudio, E. S.; Horst, M. A.; Forde, C. E.; Stern, C. L.; Zart, M. K.; Godwin, H. A. 423 Inorg. Chem. 2000, 39, 1391.

424 (19) Hayamizu, K.; Tsuzuki, S.; Seki, S.; Umebayashi, Y. J. Chem. Phys. 2011, 135, 425 084505-1.

426 (20) Atkins, P.; Overton, T.; Rourke, J.; Weller, M.; Armstrong, F.; Hagerman, M.

427 Shriver and Atkins' Inorganic Chemistry 5th ed. W.H. Freeman and Company: New 
428 York, 2010; 231.

429 (21) Chiappe, C.; Malvadi, M. Phys. Chem. Chem. Phys. 2010, 12, 11191.

430 (22) Kiefer, J.; Fries, J.; Leipertz, A. Appl. Spectrosc. 2007, 61, 1306.

431 (23) Katayama, Y. Electrochemical Aspects of Ionic Liquids 2nd ed. John Wiley \& Sons, 432 Inc, 2011; 129.

433 (24) Park, J.; Jung, Y.; Kusumah, P.; Lee, J.; Kwon, K.; Lee, C.K. Int. J. Mol. Sci. 2014, $434 \quad 15,15320$.

435 (25) Caporali, S.; Marcantelli, P.; Chiappe, C.; Pomelli, C.S. Surf. Coat. Technol. 2015, $436264,23$.

437 (26) Liu, F.; Deng, Y.; Han, X.; Hu, W.; Zhong, C. J. Alloy Compd. 2016, 654, 163.

438 (27) los Rios, A. P.; Hernandez-Fernandez, F. J.; Lozano, L. J.; Sanchez, S.; Moreno, J.

439 I.; Godinez, C. J. Chem. Eng. Data 2010, 55, 605.

440 (28) de los Rios, A. P.; Hernandez-Fernandez, F. J.; Alguacil, F. J.; Lozano, L. J.;

441 Ginesta, A.; Garcia-Diaz, I.; Sanchez-Segado, S.; Lopez, F. A.; Godinez, C.

442 Sep. Purif. Techn. 2012, 97, 150.

443 (29) Yang, F.; Kubota, F.; Baba, Y.; Kamiya, N.; Goto, M. J. Hazard. Mater. 2013, 254$444 \quad 255,79$.

445 (30) los Rios, A. P.; Hernandez-Fernandez, F. J.; Lozano, L. J.; Sanchez-Segado, S.;

446 Ginesta-Anzola, A.; Godinez, C.; Tomas-Alonso, F.; Quesada-Medina, J. J. Membrane 447 Sci. 2013, 444, 469.

448 (31) Guo, L.; Chen, J.; Shen, L.; Zhang, J.; Zhang, D.; Deng, Y. ACS Sustain. Chem. 449 Eng. 2014, 2, 1968.

450 (32) Larsson, K.; Binnemans, K. Green Chem. 2014, 16, 4595.

451 (33) Janssen, C. H. C.; Sanchez, A.; Kobrak, M. N. ChemPhysChem. 2014, 15, 3536.

452 (34) Hatfield, T.L.; Kleven, T.L.; Pierce, D.T. J. Appl. Electrochem. 1996, 26, 567.

453 (35) Hatfield, T.L.; Pierce, D.T. J. Appl. Electrochem. 1998, $28,397$. 


\begin{tabular}{|c|c|c|c|c|}
\hline $\begin{array}{c}\text { Initial } \mathrm{Ag}^{+} \\
\text {concentration } \\
(\mathrm{mM})\end{array}$ & $\begin{array}{c}\text { Temperature } \\
\left({ }^{\circ} \mathrm{C}\right)\end{array}$ & $\begin{array}{c}\text { Water } \\
\text { content } \\
\text { (ppm) }\end{array}$ & $\begin{array}{c}\text { Current } \\
\text { density } \\
\left(\mathrm{mA} \mathrm{cm}^{-2}\right)\end{array}$ & $\begin{array}{c}\text { Current } \\
\text { efficiency } \\
(\%)\end{array}$ \\
\hline 16.03 & 20 & 1000 & 0.050 & 101 \\
\hline 19.77 & 78 & -unknown- & 0.139 & 130 \\
\hline 19.77 & 20 & 4500 & 0.120 & 109 \\
\hline 19.77 & 20 & 9900 & 0.179 & 109 \\
\hline
\end{tabular}

Table 1. Influence of temperature and water content in potentiostatic electrolysis of silver triflate in ionic liquid using graphite cathode $(-0.19 \mathrm{~V}$ vs. Pt wire reference electrode). 

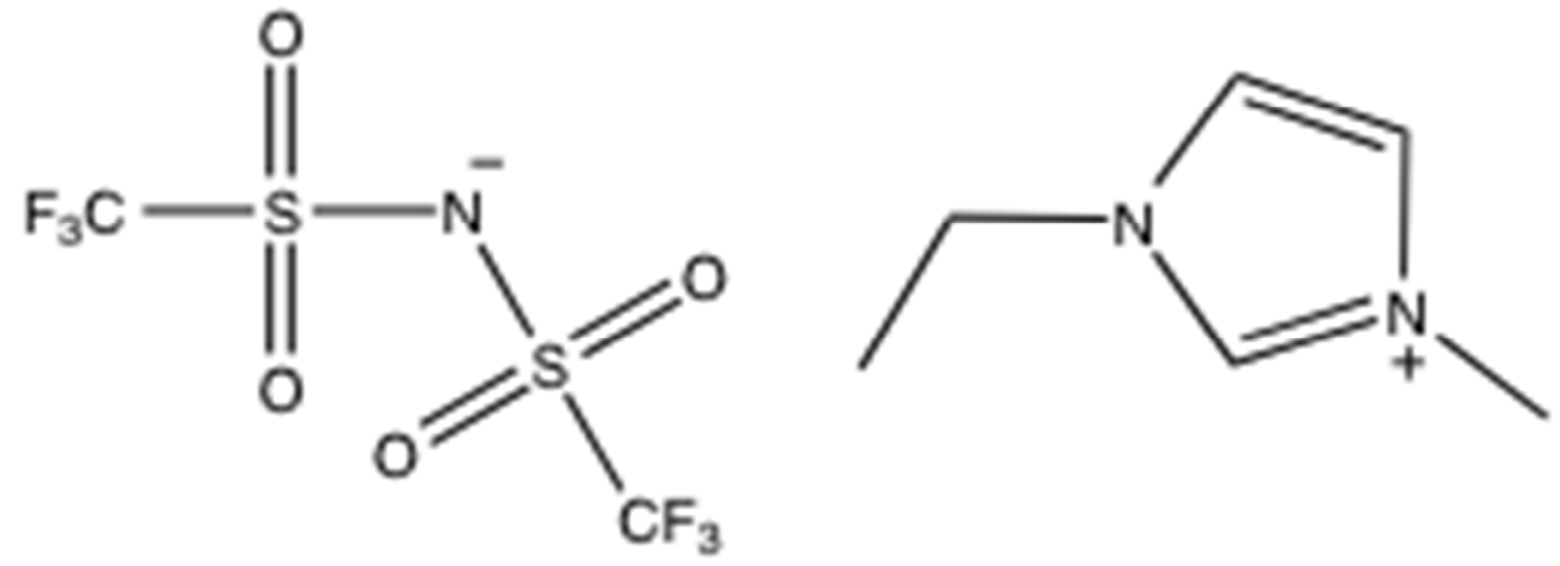

Figure 1. 1-ethyl-3-methylimidazolium bis(trifluoromethylsulfonyl) imide [EMIM][TFSI] 


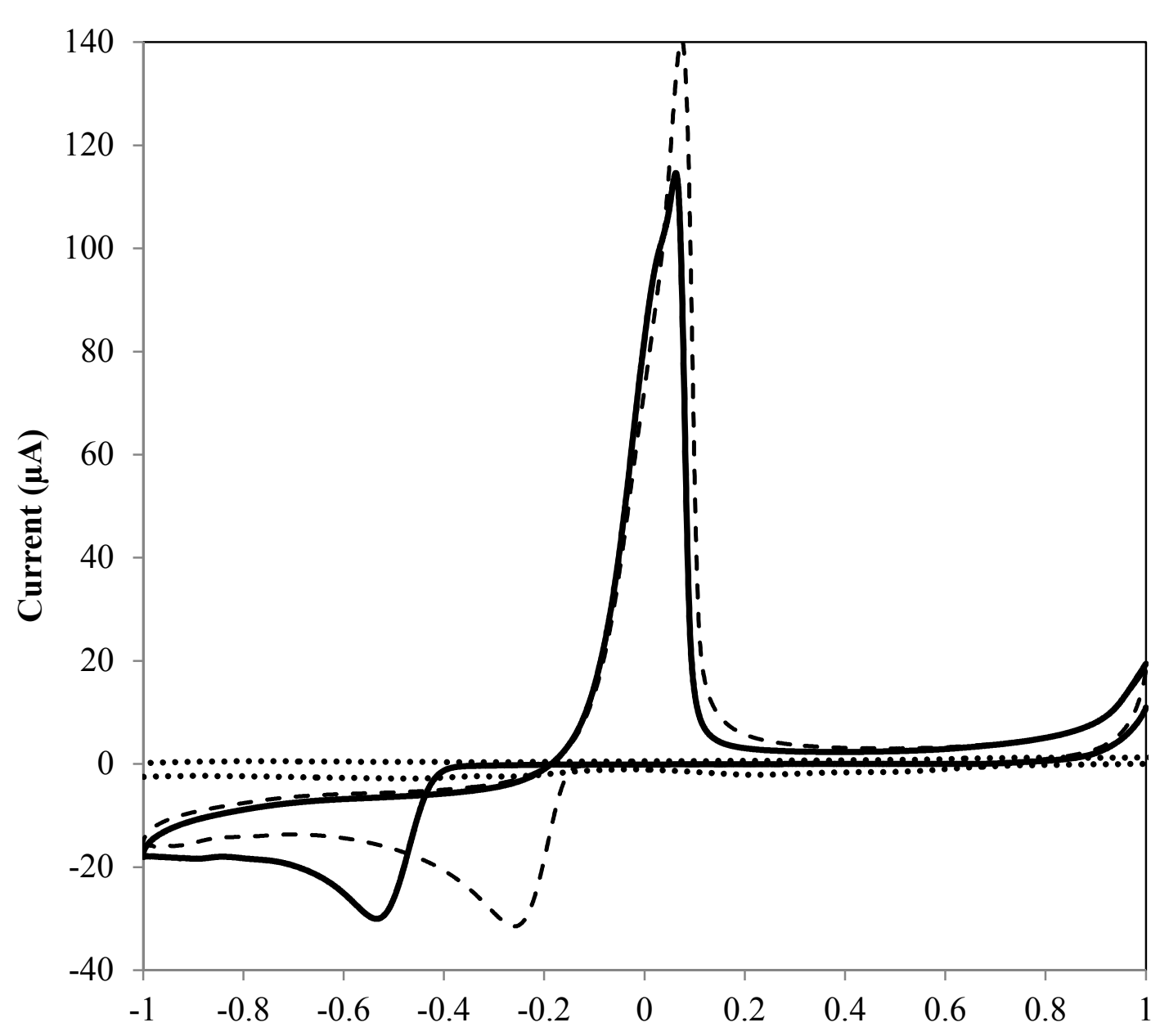

Potential (V)

Figure 2. Multiple cycles of voltammetry for the electrodeposition of $\mathrm{Ag}^{0}$ at a graphite (pencil lead) microelectrode; continuous: first cycle; dashed: second and third cycle; dotted: ionic liquid alone. 


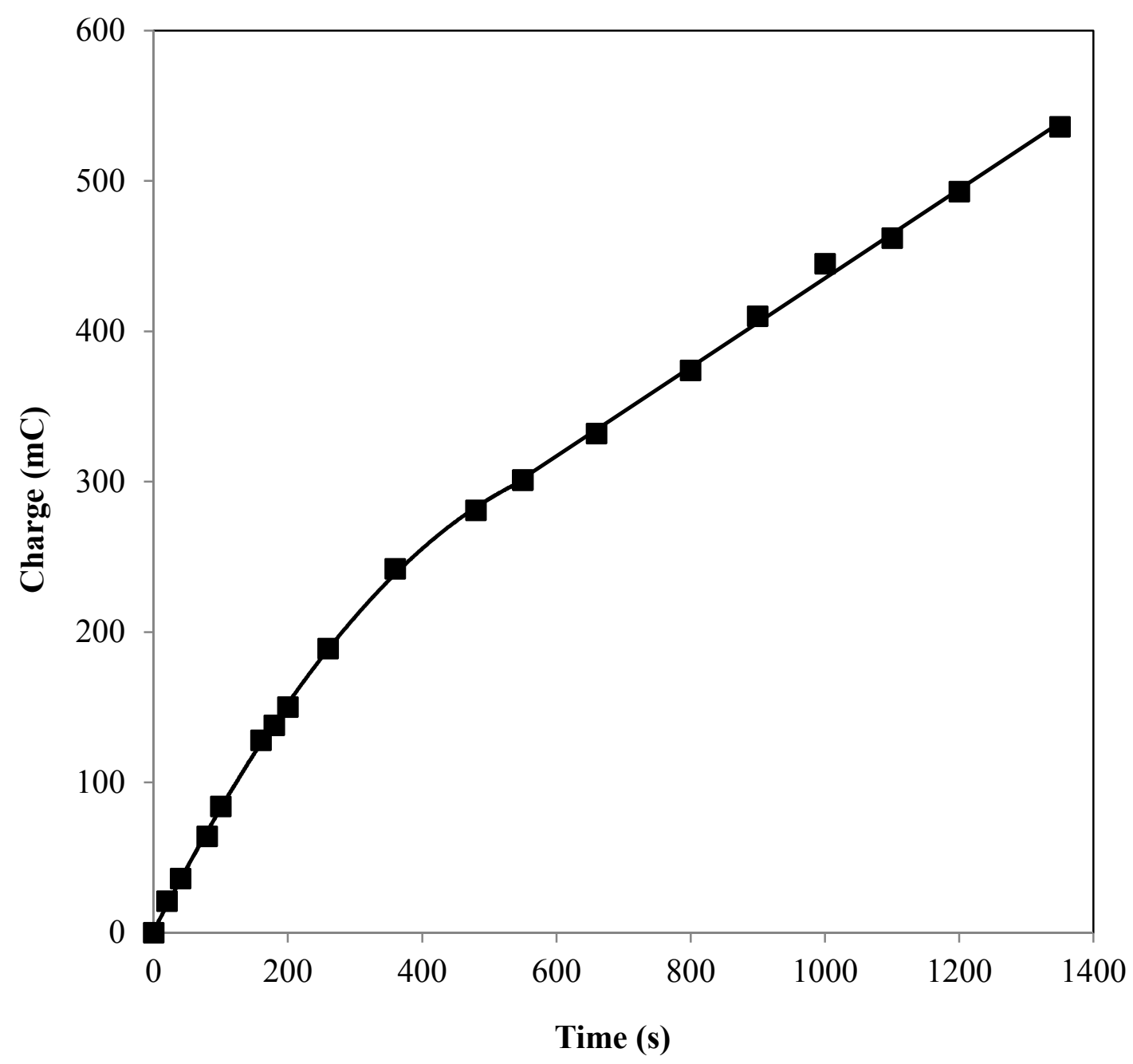

Figure 3. Coulometry plot of the potentiostatic electrolysis of $22.11 \mathrm{mmol} / \mathrm{L} \mathrm{Ag}^{+}$in [EMIM][TFSI] at -0.19 V vs. Pt reference electrode. 


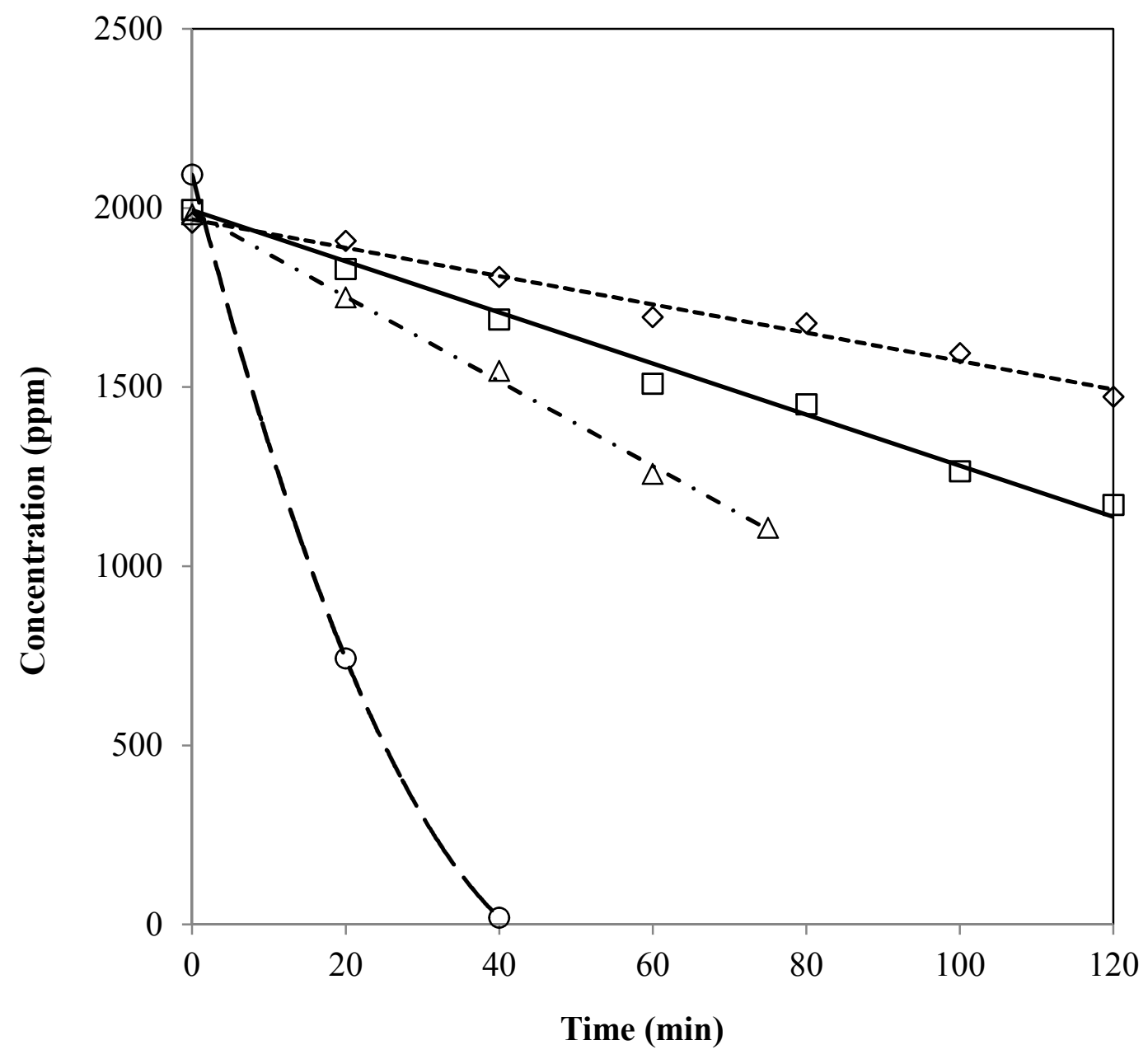

Figure 4. Depletion of silver in potentiostatic electrolysis of silver triflate in ionic liquid using Ebonex ${ }^{\circledR}$ cathode $(-0.27 \mathrm{~V}$ vs. Pt wire reference electrode, diamonds, current efficiency $98 \%$ and at $-0.40 \mathrm{~V}$ vs. Pt wire reference electrode, squares, current efficiency $79 \%$ ) and in ionic liquid with added water (from 1000 to $10000 \mathrm{ppm}$ ) using Ebonex ${ }^{\circledR}$ cathode (at $-0.27 \mathrm{~V}$ vs. Pt wire reference electrode, triangles, current efficiency $91 \%$ at $75 \mathrm{~min}$ ) compared with depletion of silver in potentiostatic electrolysis of silver nitrate in de-ionized water using Ebonex ${ }^{\circledR}$ cathode (at $-0.27 \mathrm{~V}$ vs. Pt wire reference electrode, circles, current efficiency $85 \%$ at $40 \mathrm{~min}$ ); anode: $\mathrm{Ti} / \mathrm{IrO}_{2}-\mathrm{Sb}_{2} \mathrm{O}_{5}$. 


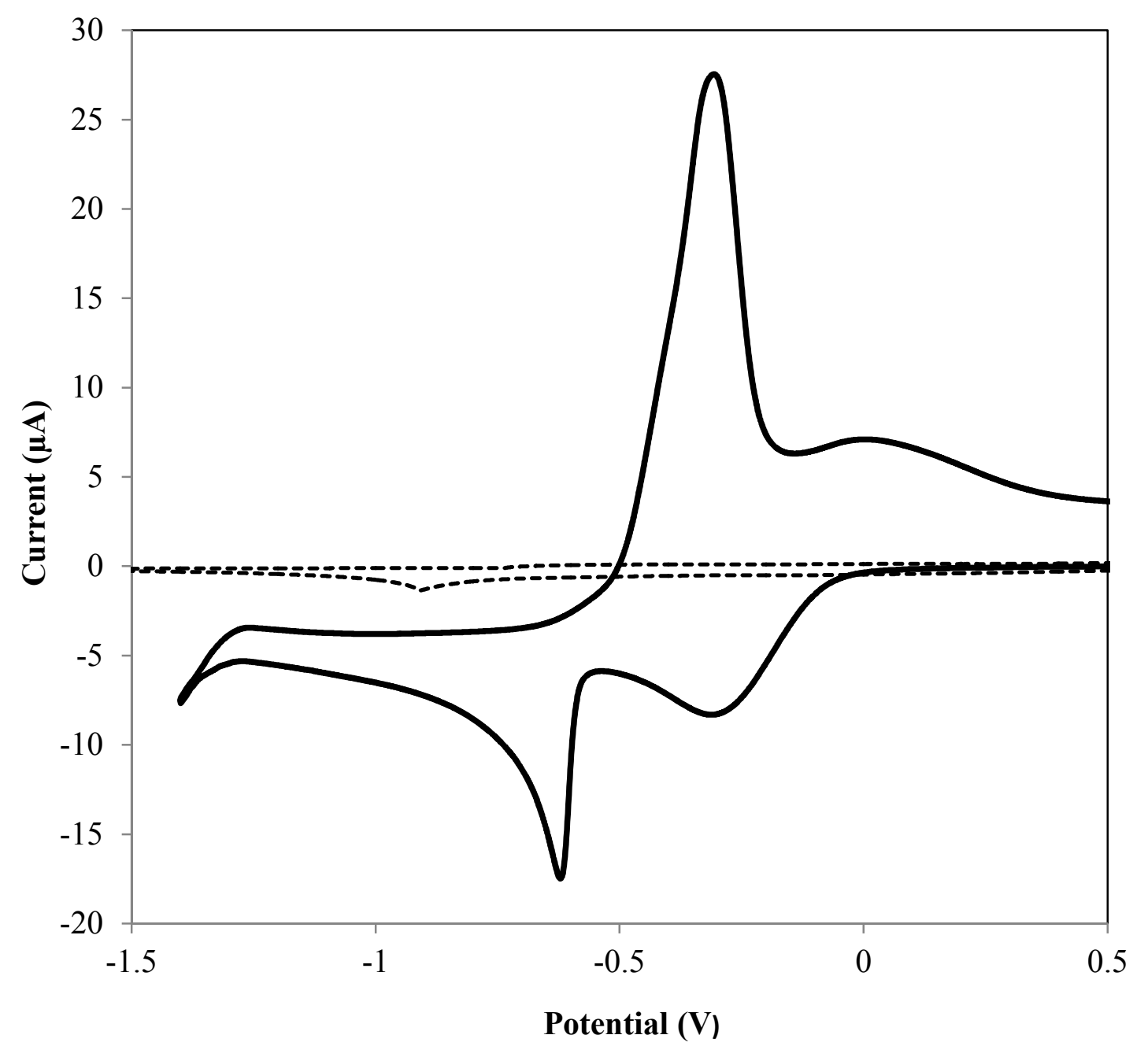

Figure 5. Overlay of the voltammograms of blank [EMIM][TFSI] and a solution of [EMIM][TFSI] containing $16.56 \mathrm{mmol} / \mathrm{L}$ of copper triflate using a platinum working electrode with a surface area of $0.0314 \mathrm{~cm}^{2}$. 


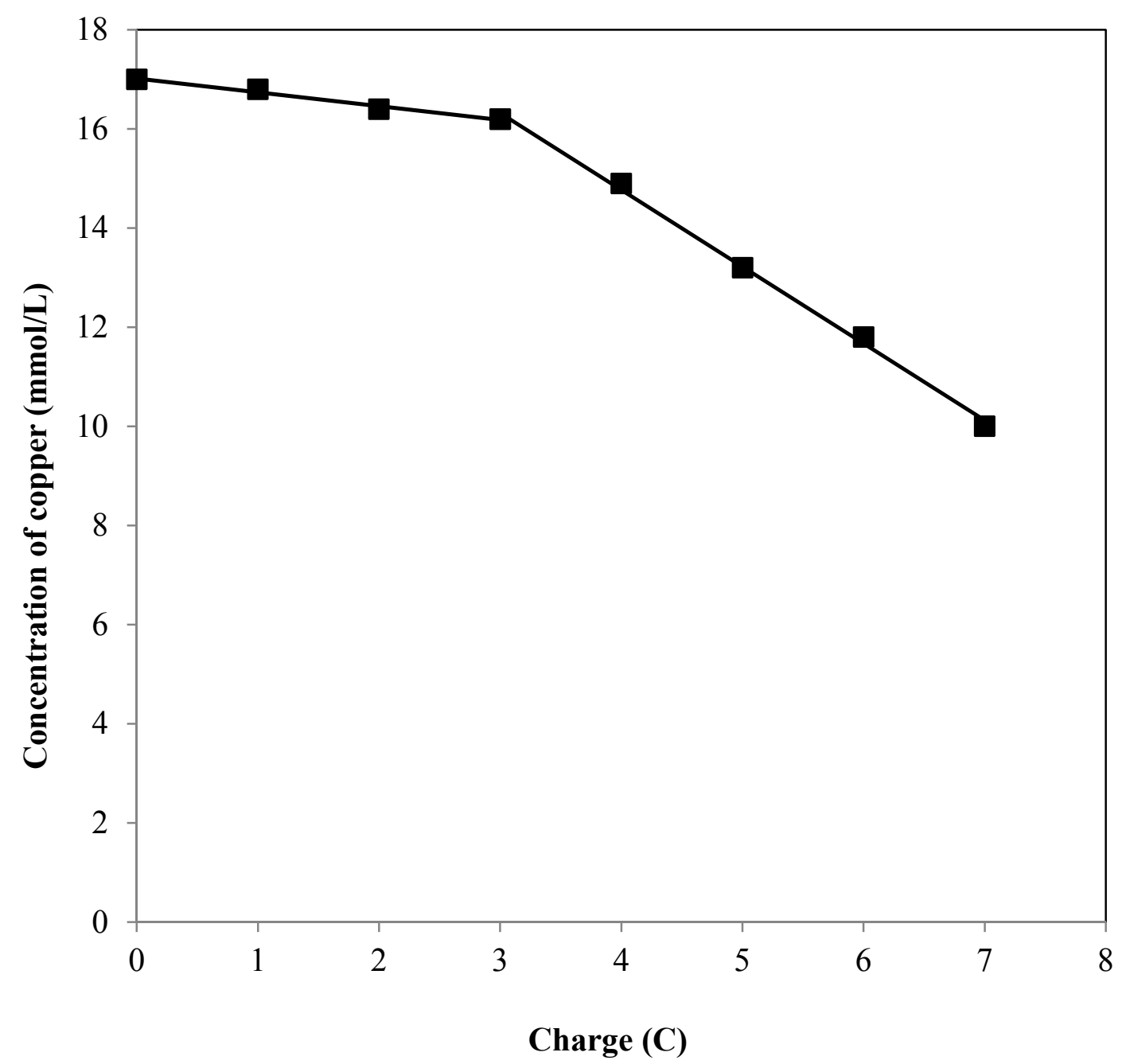

Figure 6. Loss of total copper during potentiostatic electrolysis at high water and oxygen content (not dried and not sparged) at ambient temperature with quantification using FAAS. 


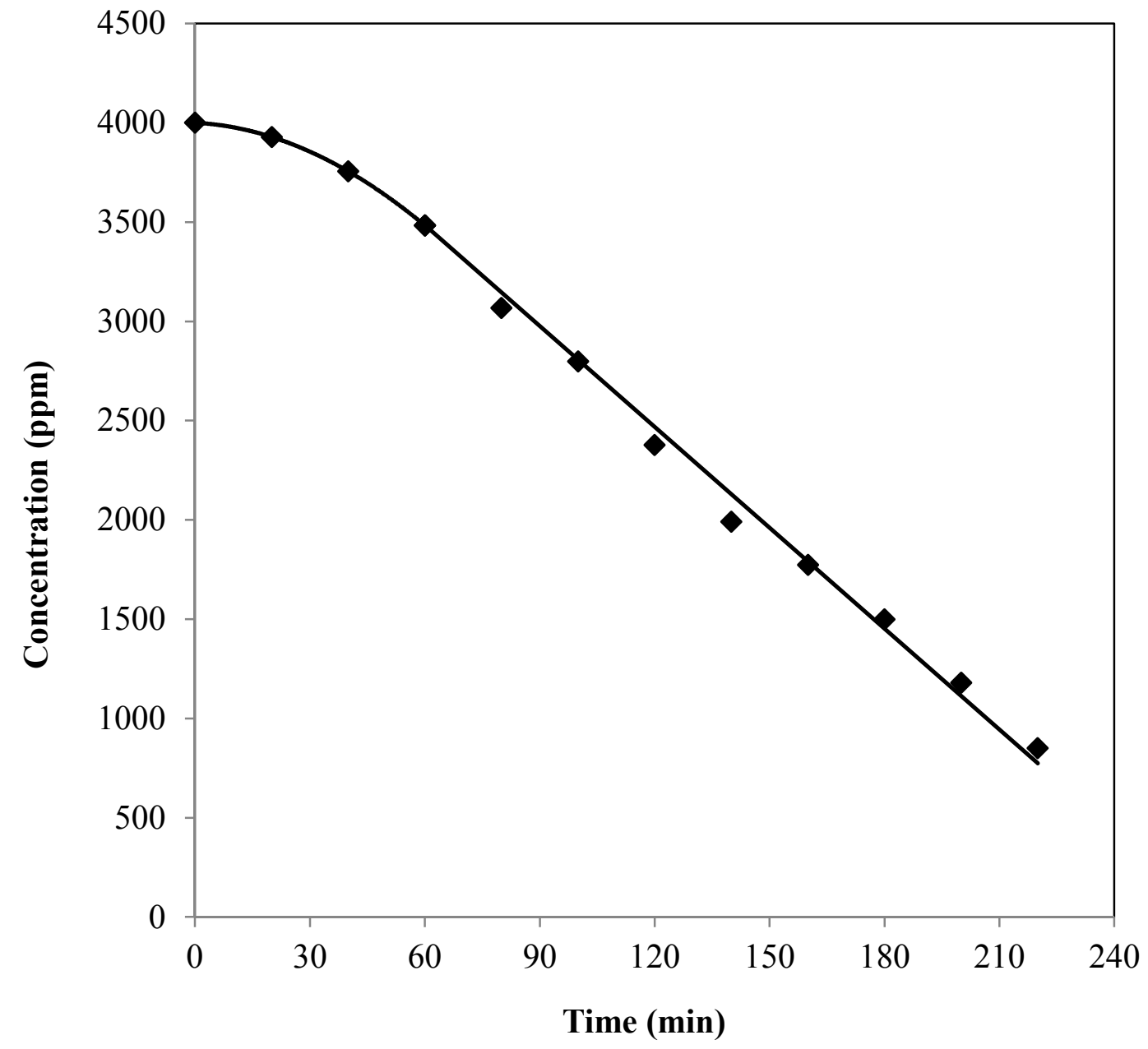

Figure 7. Depletion of lead in potentiostatic electrolysis of lead (II) trifluoroacetate, in ionic liquid and $76 \mu \mathrm{L}$ milliQ water using Ebonex ${ }^{\circledR}$ cathode (-1.204 V vs. Pt wire reference electrode) and $\mathrm{Ti} / \mathrm{IrO}_{2}-\mathrm{Sb}_{2} \mathrm{O}_{5}$ anode. Current efficiency: $111 \%$ (220 min). 


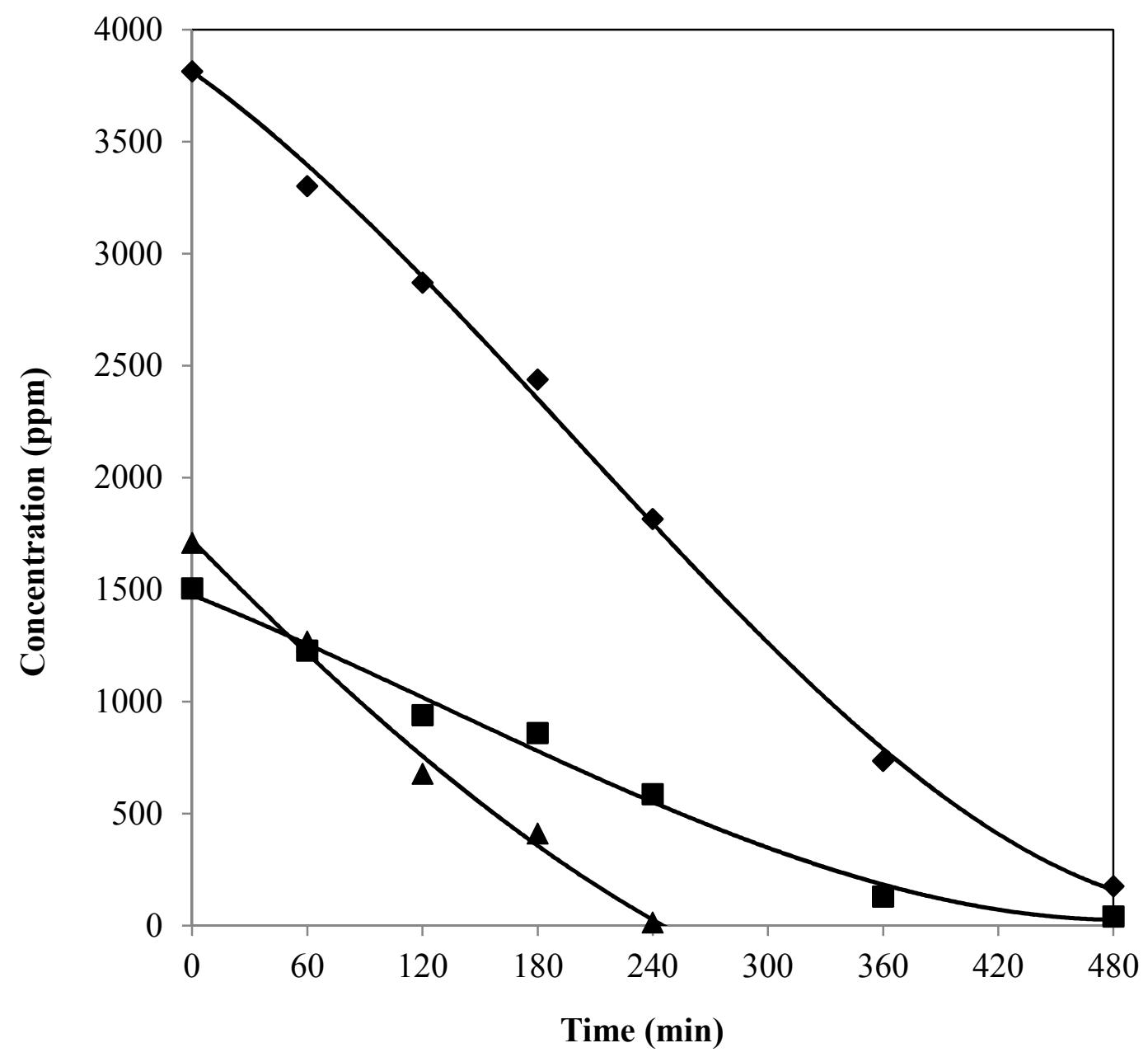

Figure 8. Depletion of lead (diamonds), copper (squares) and silver (triangles) in potentiostatic electrolysis of a mixture of lead (II) trifluoroacetate, copper (II) triflate and silver (I) triflate using Ebonex ${ }^{\circledR}$ cathode (-1.204 V vs. Pt wire reference electrode) and Ti/ $\mathrm{IrO}_{2}-\mathrm{Sb}_{2} \mathrm{O}_{5}$ anode. Current efficiency: $26 \%$ for $\mathrm{Ag}$ (240 min), 29\% for $\mathrm{Cu}$ (480 min) and 22\% for $\mathrm{Pb}$ (480 min). 